\title{
Auditoria e balanço social: o potencial intrínseco do controle social na promoção do desenvolvimento
}

\author{
Audit and social balance: the intrinsic potential of \\ social control in benefiting from the development
}

\author{
Airton Carlos Patzlaff \\ Gilson Ditzel Santos ${ }^{* *}$ \\ Miguel Angela Perondi ${ }^{* * *}$ \\ Priscila Maria Gregolin Patzlaff ${ }^{\star \star *}$
}

\begin{abstract}
Resumo: O presente artigo busca elucidar a importância do controle social na promoção do desenvolvimento, discorrendo acerca de ferramentas como auditoria e Balanço Social no mister de promover um controle social efetivo. Conceitos como transparência e confiança são utilizados no artigo sob o viés do desenvolvimento, buscando alternativas e instrumentos que alavanquem a boa governança. Com efeito, nota-se que o Balanço Social surge como ferramenta essencial na captação e análise de indicadores de sustentabilidade (dimensões econômicas, sociais e ambientais), sendo possível aperfeiçoar os processos de auditoria e controle social a partir dos demonstrativos produzidos por meio deste importante instrumento de accountability. Para desenvolver a pesquisa em questão, empregou-se o método dedutivo, tendo como principais procedimentos metodológicos a pesquisa bibliográfica e documental, as quais permitiram demonstrar - ao final do estudo - como os instrumentos de controle podem contribuir para o desenvolvimento, notadamente na seara da Administração Pública.
\end{abstract}

Palavras-chave: Desenvolvimento, Sustentabilidade, Transparência, Balanço Social.

\begin{abstract}
This article reveals the importance of social control in the pursuit of development, highlighting tools such as Audit and Social Balance in promoting a social control effective. Concepts like transparency and trust are used in the article, seeking instruments that stimulate the good governance and the development. Finally, it is clear that the Social Balance appears as an essential tool in achieving sustainability indicators (economic, social and environmental), and can improve
\end{abstract}

\footnotetext{
"Mestre em Desenvolvimento Regional pela Universidade Tecnológica Federal do Paraná (UTFPR). Auditor do Ministério Público do Estado do Paraná. Pato Branco, Paraná, Brasil. E-mail: airtonpatz@gmail.com.

"* Doutor em Administração pela FEA/USP, professor dos programas de pós-graduação em Desenvolvimento Regional e Engenharia de Produção e Sistemas da UTFPR/Câmpus Pato Branco. E-mail: ditzel@utfpr.edu.br.

${ }^{*}$ Doutorado em Desenvolvimento Rural pela Universidade Federal do Rio Grande do Sul (UFRGS). Professor do Departamento de Agrárias da UTFPR/Câmpus Pato Branco. E-mail: perondi@utfpr.edu.br.

**** Pós-graduada (lato sensu) em Gestão de Recursos Humanos pela Universidade Tecnológica Federal do Paraná (UTFPR). Servidora Pública Federal da Universidade Tecnológica Federal do Paraná. Pato Branco, Paraná, Brasil. E-mail: prikagregolin@hotmail.com.
} 
audit processes and social control from the demonstratives produced through this important instrument of accountability. To achieve these objectives we used the deductive method, through a bibliographic and documentary research, which demonstrated as instruments of control contribute to the development, mainly in Public Administration.

Keywords: Development, Sustainability, Transparency, Social Balance.

Recebido em: 11/04/2013. Aceito em: 03/03/2015.

\section{Introdução}

São inúmeras as inovações trazidas pela modernidade e pelo avanço da ciência, e não se restringem apenas ao campo das tecnologias computacionais, genéticas, telecomunicações e cibernéticas. Nota-se que a amplitude das mudanças contemporâneas atinge novas dimensões (sociais, culturais, ecológicas), até então não contempladas pelo conhecimento tradicional, de modo que conceitos como desenvolvimento e sustentabilidade são inseridos na discussão científica hodierna com uma ênfase cada vez mais intensa.

Diante disso, o objetivo dessa pesquisa consiste em esclarecer as limitações do desenvolvimento disseminado em tempos pretéritos, e as possibilidades que se vislumbram diante da permeabilidade de novos valores e novas dimensões incorporadas na análise desenvolvimentista outrora concebida no viés unidimensional e reducionista.

O pensamento científico que norteou as grandes evoluções da ciência contemporânea sobretudo nas últimas décadas - foi de essência linear-cartesiana; entretanto, a mesma fórmula que conduziu ao "progresso", hoje aponta para o colapso social e a exaustão dos ecossistemas. Para tanto, um novo modo de pensar o progresso e o desenvolvimento se faz indispensável, e é nesse sentido que a sustentabilidade passa a ser incorporada a conceitos que antes se restringiam à mera acumulação de capital e ao míope crescimento econômico.

A sustentabilidade, portanto, começa a ser vista como uma matriz essencial na construção de um desenvolvimento integral (PEDRINI e OLIVEIRA, 2007). Neste sentido, seria ilógico que os modelos de controle e mensuração dos resultados desconsiderassem os indicadores inerentes à sustentabilidade, haja vista que os processos de controle - quando bem desempenhados - possuem a capacidade de potencializar o desenvolvimento, desde que os parâmetros de avaliação sejam adequadamente estabelecidos.

As instituições públicas e privadas que almejam promover um desenvolvimento em bases sustentáveis deverão compreender a essência de tais propósitos, e - outrossim - buscar meios de implementar com eficácia essa ideologia, conscientes de que os métodos de controle e avaliação de desempenho emergem como instrumentos estratégicos nesse mister.

Ademais, tendo em vista que os atores sociais ascendem vertiginosamente no cenário contemporâneo, verifica-se que há uma propensão natural em estender o exercício do controle à participação popular. Tal tendência encontra respaldo nos benefícios sugeridos por Putnam (1996), enfatizando-se que o aumento da transparência e da confiança mútua traria vantagens que seriam compartilhadas pela coletividade por meio da redução dos custos de transação e da alavancagem do desenvolvimento, sendo esse um aspecto inerente aos argumentos contidos nas linhas ulteriores dessa discussão teórica.

Inicialmente, o artigo abordará as múltiplas dimensões do desenvolvimento, e a importância da participação social na garantia do progresso, baseando-se em autores como Freitas, Furtado, Leff e Polanyi. Em seguida, argumenta-se acerca da influência dos métodos de controle na garantia de um desenvolvimento sustentável, bem como, quais os métodos contábeis e de prestação de contas capazes de alavancar um desenvolvimento efetivo e perene.

Ressalta-se que esse estudo se caracteriza pela atualidade dos tópicos estudados, haja vista que a sustentabilidade é um tema em ascensão, e que novas técnicas de controle estão sendo im- 
plementadas na ciência administrativa, sobretudo por indivíduos comprometidos com uma gestão social e ambientalmente responsável.

Órgãos superiores de controle externo, a exemplo do Tribunal de Contas da União (2012), já reconhecem as limitações inerentes aos tradicionais mecanismos de accountability, tendo em vista que na gestão pública há preponderância de análises financeiras e jurídicas em detrimento de avaliações de desempenho amplas e interdisciplinares. Com o propósito de superar tais limitações, o TCU (2012) sugere que um enfoque mais abrangente seja adotado nos processos de prestação de contas, de modo que as instituições auditadas disponibilizem informações de natureza mais contundente e pluridimensional.

Ao incorporar variadas dimensões de apreciação, viabiliza-se uma melhor análise da performance organizacional, além de exponencializar as chances de diagnosticar procedimentos irregulares e iníquos, potencializando o alcance de um desenvolvimento sustentável a partir de múltiplas perspectivas de controle. (FRAGA e SILVA, 2010)

Quanto aos aspectos metodológicos desta pesquisa, os avanços teóricos presentes neste estudo resultaram de uma ampla pesquisa bibliográfica e documental, de caráter qualitativo, realizada no intuito de oferecer uma compreensão básica no que tange ao potencial intrínseco do controle social na promoção do desenvolvimento. Ao empregar os procedimentos metodológicos em questão, fez-se possível concluir que os instrumentos de controle ora investigados contribuem significativamente para o desenvolvimento, sobretudo ao contemplar a participação popular e viabilizar avanços na seara da Administração Pública.

Para tanto, nos tópicos iniciais do artigo são discutidas as diferentes concepções de desenvolvimento, enaltecendo-se a importância dos processos de controle na promoção de um desenvolvimento sustentável. Posteriormente, aborda-se a relevância do controle social no alcance de um progresso multifacetado, bem como, a ascensão do Balanço Social enquanto instrumento de apoio na viabilização da participação popular.

Sendo assim, a revisão bibliográfica ulterior se mostra deveras relevante, pois tem por finalidade conhecer as diferentes contribuições cien- tíficas oriundas de livros e periódicos científicos, relativas aos processos de auditoria e controle social em prol do desenvolvimento. Observa-se ainda que, na percepção de Marconi e Lakatos (2010, p. 46), "a pesquisa bibliográfica pode, portanto, ser considerada também como o primeiro passo de toda pesquisa científica". Por derradeiro, torna-se notória a pertinência desta pesquisa junto ao meio acadêmico, haja vista que a mesma poderá servir de subsídio para outros tipos de estudo acerca dos controles sociais, além de revelar utilidade no campo teórico enquanto complemento e respaldo para trabalhos científicos subsequentes, sobretudo aos que vislumbram o viés pluridimensional do desenvolvimento.

\section{As múltiplas dimensões do desenvolvimento e a participação social}

Em tempos de grandes mudanças e transformações, tal como se vislumbra hoje, nota-se que a compreensão do processo de desenvolvimento das diferentes nações e regiões tem ganhado significativa importância, haja vista a dimensão sistêmica e complexa que o conceito desenvolvimentista vem adquirindo.

O Brasil, a partir de 1988 assumiu - institucionalmente - um caráter distributivista, contrário ao caráter concentrador anterior; da mesma forma, diversos países passaram por tais transformações, mormente nas décadas de $80 \mathrm{e}$ 90, sobretudo na América Latina (MACHADO e PAMPLONA, 2008). Diante disso, e considerado o contexto competitivo hodierno, o desenvolvimento passa a ser visto como uma meta perseguida veementemente pelas nações, contemplando tanto as organizações públicas quanto privadas; com efeito, a palavra desenvolvimento passou a agregar novos significados e importância singular na conjuntura contemporânea.

O termo desenvolvimento é utilizado em discursos e justificativas das mais diversas ordens, principalmente políticas. No entanto, é um conceito transdisciplinar, sobre o qual giram discussões, e nem sempre há consenso. A economia trata de desenvolvimento praticamente como sinônimo de crescimento econômico, criação de mercados, competitividade dados estatísticos são os parâmetros para análise de resultados. Mas o desenvolvimento não se resume (ou não deve se resumir) a 
crescimento financeiro; a qualidade de vida, a inclusão social, o respeito à cultura e identidades locais fazem parte do verdadeiro desenvolvimento. (PERISSATTO, 2009, p. 111)

Na perspectiva supracitada, torna-se visível que a concepção de desenvolvimento restrita ao crescimento econômico se mostra limitada e insuficiente para proporcionar o progresso pleno e duradouro. A fim de que as metas de desenvolvimento sejam alcançadas de forma justa e equitativa, mostra-se fundamental que os resultados de natureza financeira venham acompanhados de uma melhor distribuição de renda, respeito ao meio ambiente, e da promoção de melhor qualidade de vida à população, entre outros importantes aspectos atrelados ao desenvolvimento efetivo.

Sieber (1999) defende que um desenvolvimento exitoso não é simplesmente o mesmo que crescimento econômico, sendo necessário existir um contexto adequado de tipo social, econômico, político, administrativo e cultural para alcançar o que se define como desenvolvimento. Assim, o desenvolvimento deve ser visto como um processo mais amplo que o crescimento econômico, sugerindo-se a integração das ações desenvolvimentistas junto aos contextos micro e macro ambiental, sendo pertinente considerar as particularidades regionais e locais em seus diversos âmbitos.

Doravante, a dinamização econômica deve vir acompanhada de ajustes locais, capazes de reconhecer as diversidades e potencialidades existentes dentro de cada região, ao mesmo tempo em que se estimula a participação ativa de agentes governamentais, sociais e produtivos, em uma perspectiva pluridimensional que contemple aspectos que transcendam a esfera econômica reducionista (JAIME, 2005). Considerando o desenvolvimento como um processo ativo, atrelado à participação de diferentes atores sociais e à articulação estratégica das políticas públicas, conclui-se que o desenvolvimento está intimamente ligado à cooperação entre agentes econômicos, sociedade civil, bem como, instituições públicas e privadas (SOUZA, 2009). Nesse sentido, a participação ativa dos diversos setores político-administrativos se faz essencial para que as metas de desenvolvimento sejam alcançadas de forma efetiva, ocupando função crucial a presença dos atores locais, desde que as intervenções pluralistas ocorram de forma sistêmica, regionalizada e sustentável.

Para Freitas (2011, p. 30) "[...] a noção de crescimento econômico iníquo e a qualquer custo, tão cara a economistas, juristas e políticos superficiais, passa a ser agudamente problematizada e tendencialmente desconstituída pelos intelectos mais bem equipados". A partir dessa perspectiva, nota-se que o desenvolvimento não se limita unicamente à expansão da capacidade produtiva de uma região, haja vista que o verdadeiro desenvolvimento contempla a integração e a ampla consideração do meio sócio-ambiental na esfera econômica de produção, incentivando arranjos produtivos capazes de potencializar as vantagens locais de modo responsável e estratégico perante a sociedade e o meio ambiente.

No entendimento de Furtado (1982) o verdadeiro desenvolvimento é, principalmente, um processo de ativação e canalização de forças sociais, de melhoria da capacidade associativa, de exercício da iniciativa e da criatividade. Com efeito, trata-se de um processo social, e apenas secundariamente econômico. O desenvolvimento ocorre quando, na sociedade, se manifesta uma energia capaz de canalizar, de forma convergente, forças que estavam latentes ou dispersas. Uma verdadeira política de desenvolvimento terá que ser a expressão das preocupações e das aspirações dos grupos sociais que tomam consciência de seus problemas e se empenham em resolvê-los.

Portanto, para que um desenvolvimento justo e equitativo ocorra, é fundamental que haja sistemas capazes de viabilizar uma participação efetiva da sociedade. Segundo Putnam (1996, p. 183) "[...] quanto mais desenvolvidos forem esses sistemas numa comunidade, maior será a probabilidade de que seus cidadãos sejam capazes de cooperar em benefício mútuo". Sendo assim, entende-se que os impactos de uma participação ativa da sociedade local, em sintonia com o equilíbrio sócio-ambiental, poderão amplificar as dimensões do desenvolvimento regional e garantir a perenidade do crescimento produtivo e econômico, introduzindo a real perspectiva do desenvolvimento sustentável ao contemplar as variáveis sócio-ambientais em seu escopo.

Conforme argumentos contidos nas linhas anteriores, torna-se evidente que o desenvolvi- 
mento alicerçado em bases meramente econômicas não encontra meios de subsistir, de modo que a responsabilidade por preservar o equilíbrio do ecossistema e do meio social se mostra essencial na busca por garantir resultados positivos a longo prazo.

O discurso da sustentabilidade busca reconciliar os contrários da dialética do desenvolvimento: o meio ambiente e o crescimento econômico. Este mecanismo ideológico não significa apenas uma volta de parafuso a mais da racionalidade econômica, mas opera uma volta e um torcimento da razão; seu intuito não é internalizar as condições ecológicas da produção, mas proclamar o crescimento econômico como um processo sustentável, firmado nos mecanismos do livre mercado como meio eficaz de assegurar o equilíbrio ecológico e a igualdade social. (LEFF, 2005, p. 26).

A ponderação acima se mostra extremamente pertinente, sobretudo se considerado o fato de que os recursos naturais são finitos, e que grande parte dos conflitos sociais se deve ao crescimento econômico desordenado das regiões, circunstância esta gerada por políticas públicas lineares e por visões desenvolvimentistas unidimensionais.

De acordo com Moraes e Sousa (2002), além de buscar bons resultados econômicos, as organizações devem contribuir para a sociedade e o meio ambiente onde estão inseridas, buscando um desenvolvimento sustentável na forma de ações, compromissos e práticas de responsabilidade social.

No momento em que se questionam as repercussões futuras das ações presentes, a questão da responsabilidade das gerações atuais em prol de garantir o equilíbrio e o bem-estar das gerações posteriores se faz cada vez mais intensa; tal como preconizava o Relatório Brundtland, elaborado pela Comissão Mundial para o Meio Ambiente e Desenvolvimento em 1987. Isto é, a essência do pensamento supracitado consiste em promover um desenvolvimento capaz de satisfazer as demandas hodiernas, sem comprometer a resiliência e a capacidade das gerações subsequentes atenderem suas necessidades ulteriores (próprias e inerentes).

Seguindo essa lógica, a preocupação para com o futuro deve permear todas as ações do presente, tendo em vista que as intervenções humanas ocorrem de forma sistêmica, impactando em dimensões que transcendem a escala geográfica local, e ultrapassam as medidas temporais imediatistas. Ou seja, os agentes de transformação (Estado, sociedade civil, empresas...) devem considerar os efeitos de suas ações no tempo e no espaço, adotando uma visão ampliativa, ao revés da perspectiva míope-restritiva.

Segundo Polanyi (1980, p. 161) "[...] se se deixasse a economia de mercado desenvolver-se de acordo com as suas próprias leis ela criaria grandes e permanentes males". Tal inferência se justifica pelo fato do modelo capitalista de crescimento, atrelado a uma perspectiva econômica singular e reducionista, trazer sérias distorções nas demais esferas do entorno desenvolvimentista, impactando negativamente - sobretudo - no viés sócio-ambiental.

O prisma do desenvolvimento - que outrora se restringia ao caráter unidimensional da economia - passa a integrar novas dimensões e áreas do conhecimento, de modo a exigir uma postura interdisciplinar dos atores comprometidos em promover um desenvolvimento em bases sustentáveis, sugerindo-se a cooperação e a articulação entre os indivíduos atuantes nas diferentes esferas do domínio pluridimensional (MENDES, 2010). Portanto, mostra-se crucial o reconhecimento das organizações e da sociedade em geral como peças integrantes de um sistema complexo e interdependente, devendo os agentes de transformação atuarem de forma consciente acerca da repercussão de suas intervenções nos mais diversos aspectos (econômico, social, ambiental), promovendo-se - em última análise - o desenvolvimento sustentável.

\section{O papel da auditoria na promoção do desenvolvimento sustentável}

No que tange à implementação dos processos de desenvolvimento sustentável, verifica-se que tal circunstância somente se tornará possível mediante um encadeamento de ações organizadas, sendo a Administração uma ciência elementar no alcance dos objetivos do desenvolvimento perene e equilibrado.

Entre as atividades inerentes à ciência administrativa, convém destacar o fato de que a mesma se caracteriza - sobremaneira - pelo 
mister de planejar, organizar, dirigir e controlar. Dentre as funções básicas supracitadas, ressalta-se que o objeto do presente estudo se voltará mais aos processos de controle, mormente por considerar tal atividade como elementar e preponderante no alcance da legitimidade dos atos administrativos praticados pelos agentes públicos promotores do desenvolvimento, além de garantir a eficácia das ações desempenhadas pelos representantes das organizações privadas.

Na percepção de Maximiano (2000, p. 456) "controlar, em essência, consiste em manter um padrão de comportamento, com base em informações contínuas sobre o próprio sistema e o padrão de comportamento". Portanto, a finalidade do controle é assegurar que os resultados do que foi planejado, organizado e dirigido se ajustem tanto quanto possível aos objetivos previamente estabelecidos pela gestão.

De acordo com o Núcleo de Estudos sobre Meio Ambiente e Contabilidade da Universidade Federal de Santa Catarina, a atividade de controlar envolve o monitoramento, a mensuração e a correção de desvios das atividades operacionais em relação ao planejado, com a finalidade de assegurar que os objetivos sejam alcançados em todas as áreas de atuação organizacional (PFITSCHER, 2010). Assim, considerando os processos de controle como instrumentos que auxiliam na garantia do desenvolvimento em bases sustentáveis, convém distinguir os dois principais mecanismos utilizados como ferramentas no alcance de um controle de excelência, sendo eles a Controladoria e a Auditoria.

De modo convencional, tem sido designada a nomenclatura controladoria para os controles internos realizados de forma permanente pelas organizações, ao passo que a auditoria tem sido vista como um controle externo realizado eventualmente pelas entidades. Segundo Chaves (2009, p. 15), torna-se possível distinguir objetivamente a diferença entre controles internos e controles externos, sendo a auditoria "batizada de controle externo. Recentemente, surgiu a denominação de controladoria fazendo referência ao controle interno".

No que tange à implementação dos processos de controle (de modo geral), a auditoria é a técnica que mais se desenvolveu nas últimas décadas, e teve um importante papel no aprimoramento das instituições públicas e privadas em países como Inglaterra, Estados Unidos e Canadá. (TRIBUNAL DE CONTAS DA UNIÃO, 2000).

A causa da evolução da auditoria, que é decorrente da evolução da contabilidade, foi a do desenvolvimento econômico dos países, síntese do crescimento das empresas e da expansão das atividades produtoras, gerando crescente complexidade na administração dos negócios e das práticas financeiras como uma força motriz para o desenvolvimento da economia de mercado. (ATTIE, 1998, p. 27)

Dentro do prisma em questão, nota-se que os aprimoramentos da auditoria, assim como o desenvolvimento dos países, interagem de forma recíproca. Ou seja, na medida em que se amplia a complexidade na administração, ascende-se a demanda por controles mais rigorosos; da mesma forma, a auditoria se aprimora com o propósito de servir como mecanismo de propulsão a um desenvolvimento integrado e sustentável.

As técnicas de controle têm por finalidade auxiliar as organizações a alcançarem seus objetivos por meio de uma abordagem sistêmica e disciplinada de avaliação, visando promover a melhoria da eficácia dos processos, além de aperfeiçoar as operações e garantir melhores resultados. Seguindo essa perspectiva supracitada, os autores Menegussi e lanesko (2008, p. 10) inferem que "[...] a Auditoria, na atualidade, é um serviço que contribui para o desenvolvimento da entidade, ajuda no aprimoramento dos controles internos, permite a detecção de irregularidades, e também aprimora o desenvolvimento".

Portanto, assevera-se que as técnicas de controle, a exemplo da auditoria, exercem uma espécie de função preventiva, reparadora e moralizadora dentro das organizações em seus mais diversos aspectos, de modo que as habilidades exigidas para uma atuação efetiva dos auditores passam a adquirir nuances cada vez mais multidisciplinares.

Entende-se por auditoria a atividade multidisciplinar, de natureza singular, que compreende várias formações profissionais para análises intelectuais, pormenorizadas e personalísticas em documentos concretos e idôneos. Seu objetivo é emitir relatórios fundamentados sobre os procedimentos contábeis, administrativos, financeiros ou patrimoniais, 
incluindo pagamentos, prestações de contas, demonstrações contábeis, procedimentos fiscais, tributários, jurídicos, financeiros e de pessoal. (BATISTA, 2011, p. 27)

Assim sendo, percebe-se que as noções fragmentadas da realidade - as quais predominavam em análises e prognósticos pretéritos - passam a adquirir novas dimensões, de modo que a auditoria deixa de ser uma atividade restrita à ciência contábil, na medida em que as demandas por um desenvolvimento sustentável exerceram presença mais intensa na gestão pública e privada.

Iniciou-se o processo de ruptura entre Auditoria e Contabilidade, com o surgimento das auditorias operacional e de gestão e o consequente desencadeamento de outros tipos de auditoria, passando a requerer conhecimentos multidisciplinares e, profissionais de diversas formações acadêmicas. Os auditores começaram a atender necessidades de melhoria dos controles da entidade como um todo. A preocupação com a competitividade, a qualidade e até com o meio ambiente ampliaram o foco de atenção, antes restrito à contabilidade, para as estratégias de ação. (PINHO e ARAÚJO, 2002, p. 3)

Destarte, a eficácia dos controles pode ser vista como um fator estratégico na gestão organizacional, haja vista a possibilidade de afastar comportamentos displicentes ou equivocados por meio da apuração e correção de desperdícios, improbidades, negligências e omissões, não se restringindo os controles - unicamente - a uma análise dos aspectos contábeis e financeiros. Afinal, conforme Moraes e Sousa (2002, p. 8), diante de uma realidade marcada pela consciência acerca das limitações do pensamento unidimensional na elaboração de indicadores de avaliação, "[...] é muito importante ter clara a estrutura das variáveis contábeis, propriamente econômicas, mas também se torna decisivo avaliar o peso das variáveis mais propriamente socioculturais".

Todas as organizações precisam encontrar meios de atingir seus objetivos e sustentá-los no longo prazo, cumprindo suas metas com responsabilidade e otimizando seus resultados de modo estável, a fim de justificar e preservar sua existência. Nesse viés, os mecanismos de controle são concebidos como instrumentos fundamentais em prol de garantir a perenidade das organizações, buscando conciliar o cumprimento dos objetivos estratégicos ao equilíbrio sócio-ambiental.

Diante disso, mostra-se fundamental que os auditores sejam guiados por uma postura pluridimensional e interdisciplinar, acompanhada de prudência, de perícia e de técnicas adequadas em seus processos de controle. Segundo Tinoco (2001) o exercício da consciência moral, cívica e ética emana da ampla compreensão do auditor acerca de seu papel no desenvolvimento da sociedade, o que, em um momento como o presente em que se busca um desenvolvimento alicerçado em dimensões múltiplas, torna-se notória a importância de se implementar medidas mais amplas e condizentes com o aprimoramento pluridimensional que se almeja nas organizações, de modo que a auditoria de vanguarda sirva como mecanismo apto a alavancar o desenvolvimento sustentável.

\section{O Balanço Social e a influência da auditoria na mensuração dos resultados}

Como já vinha sendo discorrido nas seções anteriores, verifica-se que os conceitos de desenvolvimento e de auditoria passaram a adquirir novas dimensões na atual realidade em que se busca a sustentabilidade. Por consequência, torna-se fundamental o surgimento de novos aparatos e demonstrativos capazes de subsidiar a atuação pluridimensional do auditor que visa promover o desenvolvimento sustentável.

De acordo com Aguiar (2002, p. 16) mostra-se crucial que as organizações "[...] mudem a concepção estritamente econômica e financeira que ainda predomina, e se atentem para as mudanças que vêm ocorrendo no ambiente externo, adotando uma postura mais comprometida com as questões sociais". Assim, levando em consideração as mudanças ocorridas no cenário mundial e na esfera dos controles organizacionais, verifica-se que entre os instrumentos capazes de proporcionar informações condizentes com as novas demandas no âmbito do desenvolvimento e da auditoria, está o Balanço Social:

O Balanço Social é um conjunto de informações sobre as atividades desenvolvidas por uma empresa, em promoção humana e social, dirigidas a seus empregados e à comunidade 
onde está inserida. Através dele a empresa mostra o que faz pelos seus empregados, dependentes e pela população que recebe sua influência direta. (TREVISAN, 2002, p. 3)

O Balanço Social é um instrumento apto à complementar as tradicionais demonstrações contábeis, as quais se restringem aos aspectos de natureza meramente patrimonial, financeira e econômica da entidade, por vezes não condizentes com a proposta mais abrangente de alavancar o desenvolvimento sustentável. De acordo com Almeida (2002, p. 35) "[...] a prática do desenvolvimento sustentável exige uma combinação equilibrada dos mecanismos de comando-e-controle, auto-regulação e instrumentos de mercado" e, nesse sentido, infere-se que as demonstrações contábeis servem como um importante instrumento de acompanhamento e controle sobre os agentes sociais (governos, empresas e organizações da sociedade civil), muito embora apresentem restrições que carecem ser superadas.

A fim de melhor explicar a questão em pauta, José Eduardo Sabo Paes discorre acerca das limitações dos demonstrativos contábeis divulgados tradicionalmente, e quais os mecanismos capazes de superar tais limites.

Percebe-se que a função desses demonstrativos divulgados fica limitada à ideia de apuração, controle e mutação do patrimônio de uma determinada entidade contábil, sem se preocupar direta ou indiretamente com outros fatores inerentes ao ambiente em que a pessoa jurídica (com ou sem fins lucrativos) está inserida. [...] Diante da constatação do limite dos demonstrativos tradicionalmente elaborados e divulgados e da exigência de que as empresas divulgassem informações de caráter social e ecológico, como complemento daquelas demonstrações, é que surgiu a ideia de Balanço Social. (PAES, 2010, p. 528)

A partir da proposta trazida pelo autor, nota-se que as limitações antes apresentadas pelos demonstrativos contábeis tradicionais passam a ser superadas pelo Balanço Social, haja vista o caráter sistêmico, abrangente e multidisciplinar deste novo demonstrativo. Assim, abre-se a possibilidade de se exercer um controle mais contundente sobre as organizações, ampliando-se as chances de promover o desenvolvimento em bases sustentáveis.
Nesse viés, entende-se que o Balanço Social, por ser um demonstrativo desenvolvido pela contabilidade para evidenciar as ações das entidades em beneficio do bem-estar social e ambiental, contribui efetivamente para o desenvolvimento sustentável, tendo em vista a evidenciação de indicadores aptos a retratar a perspectiva dos principais elementos constitutivos, tais como: Capital Tradicional, Capital Empresarial, Capital Humano, Capital Natural e Capital Social. (LIMA e PINHEIRO, 2004)

Os benefícios que advém da utilização do Balanço Social podem ser inúmeros (viabilização de controles periódicos, promoção da responsabilidade social, melhoria da imagem organizacional, estímulo a ações sócio-ambientais...), sobretudo se o mesmo for elaborado e disponibilizado de forma transparente e objetiva, ocasião em que os organismos controladores - e stakeholders ${ }^{1}$ poderão tomar conhecimento acerca da atuação e repercussão das atividades organizacionais no meio externo.

Ressalta-se que os sistemas de transparência e participação social representam um elemento estratégico capaz de alavancar o desenvolvimento. De acordo com Putnam (1996, p. 186) "as regras de reciprocidade generalizada e os sistemas de participação cívica estimulam a cooperação e a confiança social porque reduzem os incentivos a transgredir, diminuem a incerteza e fornecem modelos para a cooperação futura".

O Balanço Social surge como uma proposta intimamente ligada ao conceito de ética e responsabilidade social. Nesse sentido, a transparência atende às expectativas da sociedade, haja vista que, por meio da divulgação sistematizada dos resultados obtidos no exercício, é possível mensurar a coerência entre o discurso e as práticas organizacionais.

Um dos instrumentos notáveis que incentiva a atitude de comunicação transparente da empresa com os públicos com os quais se relaciona é o Balanço Social. [...] Por meio do Balanço Social, a empresa mostra o que fez pelos empregados e seus dependentes e pela população sobre quem exerce influência direta. (RICO, 2004, p. 76)

\footnotetext{
${ }^{1}$ De acordo com Freitas et al. (2012) o conceito mais amplo e disseminado sobre stakeholders é aquele que os definem como todos que afetam ou são afetados pelas organizações (proprietários, clientes, fornecedores, governo, instituições financeiras...).
} 
Portanto, torna-se evidente que mediante a elaboração do Balanço Social as organizações abrem a possibilidade da população tomar conhecimento acerca dos compromissos e responsabilidade assumidos perante a comunidade em sentido lato, aprimorando e difundindo o vínculo entre a ética, a responsabilidade e os processos produtivos. $^{2}$

Segundo Reis e Medeiros (2011), são várias as instituições que tem utilizado o Balanço Social como instrumento de publicação de seus demonstrativos sociais, econômicos e ambientais; como exemplo de entidades brasileiras, cita-se: Petrobras (Petróleo Brasileiro S/A), Banco do Brasil S/A, Banco Itaú, Furnas Centrais Elétricas, Infraero (Empresa Brasileira de Infraestrutura Aeroportuária) e Copel (Companhia Paranaense de Energia Elétrica S/A).

De acordo com Silva et al. (2013), uma análise dos Balanços Sociais elaborados pela Petrobras entre 1998 e 2009, revelou que a utilização do Balanço Social por parte desta organização elevou o comprometimento institucional nos itens relativos à sua atuação socioambiental. Já na perspectiva bancária, Ventura (2005) destaca que a utilização do Balanço Social por instituições como o Banco do Brasil S/A e o Banco Itaú aprimoraram significativamente a performance social e ambiental destas organizações, implementando este demonstrativo como um forte diferencial competitivo.

Nesse sentido, as pesquisas desenvolvidas por Silva et al. (2013) revelaram que existe uma forte correlação entre o investimento em ações socioambientais e a elevação do faturamento, de modo que as ações empreendidas pela Petrobras ao divulgar seu Balanço Social repercutiram sensivelmente no comprometimento da entidade em projetos sociais e ambientalmente responsáveis, influenciando diretamente na imagem pública da organização e no aumento de sua receita líquida.

Empresas com boa governança, responsabilidade social e ambiental possuem diferencial competitivo em suas atividades, logo, nesse sentido, há que se ter consciência de que se

\footnotetext{
2 Para Putnam (1996, p. 183) "quanto maior for a comunicação (tanto direta quanto indireta) entre os participantes, maior será a sua confiança mútua".
}

deve ir além, já que cada vez mais a proteção ao meio ambiente vem se tornando uma preocupação de muitas empresas, de formadores de opinião e de parcela significativa da população, em várias partes do mundo. A elaboração, a publicação e a divulgação do Balanço Social pelos gestores constitui-se no melhor exemplo de Accountability. (TINOCO, 2010, p. 31).

Em face da repercussão e da importância atribuída aos dados divulgados pelo Balanço Social, nota-se a preocupação de que os resultados apresentados nesses demonstrativos sejam inteligíveis e correspondam à realidade, tendo em vista que poderá ocorrer a deturpação em tais índices caso determinadas organizações desejem mascarar resultados negativos perante os stakeholders.

Nessa trajetória, não basta que informações sejam disponibilizadas ao cidadão. Necessário se faz que essas espelhem fidedignamente os atos de gestão praticados pela administração. Diante desse contexto, destaca-se o papel da contabilidade e auditoria, os quais possuem a obrigação de elaborar e fiscalizar a execução contábil, financeira, orçamentária, operacional e patrimonial. (MENDES, OLEIRO e QUINTANA, 2008, p. 13).

Como já havia sido discorrido na seção anterior, a auditoria exerce uma função analítica essencial no processo de garantir a veracidade e a correta interpretação das informações disponibilizadas pelas organizações por meio de seus demonstrativos. De acordo com Ferreira (2004, p. 45), "considerando o Balanço Social como sendo uma peça contábil, torna-se necessário, que o mesmo também seja auditado, como forma de se garantir que as ações estejam sendo efetivamente praticadas".

Sendo assim, torna-se evidente que a auditoria do Balanço Social permite avaliar a veracidade, a eficiência e o equilíbrio da entidade na condução de suas ações, identificando o grau de comprometimento de todos os seus atores com a missão e os propósitos da organização, formulando - inclusive - recomendações de melhoria. Nesse sentido, a auditoria do Balanço Social almeja avaliar os níveis de autenticidade das informações, ao mesmo tempo em que busca mensurar os dados apresentados e transmitir 
com clareza as conclusões obtidas por meio da leitura dos indicadores.

\section{O Balanço Social como instrumento de apoio no controle social da gestão}

Pela disseminação do Balanço Social, nota-se que as possibilidades da população exercer um controle social efetivo sobre as organizações se tornam mais contundentes e viáveis, sobretudo na gestão de recursos públicos que tanto interessa aos cidadãos enquanto contribuintes.

A atual Constituição Federal do país previu a participação popular na gestão da res publica. Porém, para que esse princípio seja amplamente concretizado como também para que a cidadania possa se consolidar cada vez mais no país, a administração pública precisa apresentar soluções pragmáticas, como transparência, responsabilidade (accountability) e controles eficazes. (MENDES, OLEIRO e QUINTANA, 2008, p. 13).

A gestão da coisa pública tem um foco preponderantemente social e não financeiro; nesse sentido, entende-se que o significado do "lucro" está no benefício que as ações do Estado geram para a coletividade. Destarte, deve-se incentivar a implementação de ferramentas que possibilitem a realização de controles eficazes (a exemplo do Balanço Social), e processos - como a auditoria - que atribuam aos demonstrativos uma maior confiabilidade e inteligibilidade. ${ }^{3}$

Sabe-se que os fenômenos sociais, econômicos e ambientais existentes no contexto hodierno são característicos de uma sociedade complexa; consequentemente, tal conjuntura traz sérias implicações ao desenvolvimento. $\mathrm{Na}$ perspectiva de Douglass North (2003) as vantagens do oportunismo, da trapaça e da transgressão aumentam nas sociedades complexas, sendo fundamental que haja recursos capazes de assegurar a confiança dos indivíduos nas instituições modernas. Seguindo essa lógica, quanto mais transparentes forem as entidades,

\footnotetext{
${ }^{3}$ De acordo com Sen (2000) as garantias de controle e transparência referem-se à necessidade humana de obter clareza e honestidade em suas relações sociais, sendo esta uma garantia de liberdade instrumental do gênero humano que possui um papel relevante na inibição da corrupção, da irresponsabilidade financeira e de transações ilícitas.
}

maior será a confiança das pessoas em investir e manter relações de grande escala, de tal sorte que sem este quesito elementar não existirá desenvolvimento efetivo, tampouco crescimento econômico.

A transparência na condução das atividades organizacionais abrange tanto os resultados apresentados por entidades públicas como entidades privadas, entretanto, restringindo-se a interpretação da transparência à gestão pública, é possível observar que a obrigação de prestar contas à sociedade (accountability) se torna ainda mais necessária e vinculada à legislação. Neste sentido, o princípio da transparência se apresenta como um dos pressupostos da gestão pública responsável, tendo sua relevância reconhecida na Lei Complementar $n^{\circ} 101$, de 04 de maio de 2000 (Lei de Responsabilidade Fiscal). Assim, nota-se que a resposta do governo para o cidadão participativo tangencia princípios como a publicidade, o acesso à informação, e a prestação de contas. (PIRES, 2009).

Não obstante, os mecanismos propostos pela LRF não surgem como panaceia do desenvolvimento, mas como instrumentos de apoio no gerenciamento das receitas, enaltecendo a essencialidade de um planejamento efetivo e transparente, entre outros importantes procedimentos administrativos capazes de estimular o alcance da governança pública. Assim é que inovações como a trazida pela Lei Complementar $101 / 2000$ (LRF), no intuito de minimizar a rigidez burocrática inerente à gestão pública tradicional, trouxeram de maneira mais presente conceitos modernos de planejamento e transparência ao universo público, facilitando o alcance da eficiência gerencial, prevista como princípio constitucional, sem afastar a legalidade estrita. Sob tal perspectiva, verifica-se no Balanço Social uma ferramenta diretamente ligada aos conceitos de responsabilidade implícitos na LRF.

Segundo Pires (2009, p. 7) “[...] o Balanço Social se apresenta como elemento fortalecedor do controle da gestão pública, bem como da transparência. Considerando sua publicidade, possui caráter de fácil compreensão e de utilidade na tomada de decisão". Além disso, nota-se que uma das principais virtudes do Balanço Social consiste na ampla transparência, a qual viabiliza o controle social da gestão: 
Mais do que resgatar a cidadania, pretende-se resgatar a gestão pública. Por isso o Balanço Social se apresenta como uma alternativa adicional para o controle social da gestão pública. Ao mesmo tempo ele remete o governo a implementar modelos de gestão, focados nos resultados e na responsabilização. Fortalece o papel da controladoria a fim de aperfeiçoar estes sistemas informacionais. (PIRES, 2009, p. 5)

A circunstância acima exposta remete às recentes transformações ocorridas na esfera pública, sobretudo se considerada a crescente importância atribuída aos mecanismos de controle voltados aos resultados (a posteriori), ao contrário dos tradicionais meios de controle (a priori) que predominavam no modelo burocrático de gestão.

Segundo Slomski (2003) a administração pública burocrática surgiu em meados do século XIX, na época do Estado liberal, como forma de combater a corrupção e o nepotismo patrimonialista, utilizando como instrumentos centrais o rígido formalismo e a impessoalidade, em síntese, o poder racional-legal. No entanto, a partir da década de 1980, emergiu o modelo de gestão conhecido como administração pública gerencial, no qual as entidades públicas passam a existir para o atendimento das necessidades sociais, orientadas por missões condizentes com as novas demandas emergentes.

Com a adoção desse modelo, os processos de controle devem ser deslocados para a posteriori, concedendo maior autonomia ao agente público no sentido de responsabilizá-lo pelos seus atos, ao revés do controle rígido em cada etapa do processo administrativo conforme preceituava o modelo burocrático.

Portanto, este controle deslocado para a posteriori, contemplando a responsabilização do agente público, se reporta a um conceito muito utilizado na atualidade que é o da accountability. O conceito de accountability se vincula ao dever que o agente público tem de prestar contas de seus atos e de assumir responsabilidade sobre estes. ${ }^{4}$

Sendo assim, observa-se que existe uma notória tendência na administração pública bra-

\footnotetext{
${ }^{4}$ Tal conceito norteou de forma efetiva a edição da Lei Complementar $n^{\circ}$ 101/2001 - Lei de Responsabilidade Fiscal (PAIVA, 2004).
}

sileira em se efetuar uma transição do modelo burocrático (rígido, voltado a si mesmo e aos processos internos) para o modelo gerencial (flexível, eficiente, voltado para o atendimento do cidadão e aos resultados), haja vista as transformações hodiernas e as recentes inovações implementadas com vistas a aumentar a eficiência gerencial e maximizar o atendimento dos anseios populares.

\begin{abstract}
A adoção do modelo gerencial, com o controle por resultados e com a delegação a organizações sociais para a execução de serviços públicos, faz com que apenas o controle governamental instituído não seja suficiente para controlar a execução das políticas governamentais. Desse modo, iniciou-se o processo de criação de estruturas que permitissem aos cidadãos exercerem, diretamente ou por meio da sociedade civil organizada, o controle sobre a Administração Pública auxiliando a estrutura de controle governamental. (PAIVA, 2004, p. 28)
\end{abstract}

Embora a adoção de mecanismos como o Balanço Social estejam ganhando uma importância cada vez maior na sociedade brasileira ${ }^{5}$, verifica-se que a ausência de obrigatoriedade legal acaba minimizando o número de organizações comprometidas com a divulgação de seus resultados sócio-ambientais, e - com isso - reduzindo as possibilidades de um controle social efetivo. Todavia, várias organizações já elaboram e divulgam o seu Balanço Social no Brasil, circunstância advinda de um trabalho pioneiro desenvolvido pelo sociólogo Herbert de Souza, na década de 1990, por meio do Instituto Brasileiro de Análises Sociais e Econômicas - IBASE (PAES, 2010). ${ }^{6}$

Tendo em vista que a legislação ainda não impôs a obrigação normativa das entidades divulgarem o seu Balanço Social, nota-se que o compromisso a ser firmado é com a sociedade (e não com a lei), expresso por ações proativas

\footnotetext{
${ }^{5}$ As razões que impelem as entidades a divulgarem tais demonstrativos estão intimamente ligadas a questões de ordem moral ou até mesmo mercadológica.

${ }^{6}$ Na realidade brasileira, evidencia-se que ideias incipientes acer-
ca da elaboração do Balanço Social começaram a ser discutidas
na década de 1970, entretanto, apenas em meados de 1980 é
que surgiram os primeiros Balanços Sociais. A partir da déca-
da de 1990, graças aos parâmetros desenvolvidos pelo IBASE,
vislumbra-se que corporações de diferentes setores passaram a
publicar o seu Balanço Social anualmente, independentemente
da obrigatoriedade legal.
} 
vinculadas ao papel que as organizações ocupam na sociedade, sendo natural e coerente que as entidades busquem um modo de prestar contas ao meio em que se inserem.

A organização, nesse sentido, assume obrigações de caráter moral, além das estabelecidas em lei, mesmo que não diretamente vinculadas a suas atividades, mas que possam contribuir para o desenvolvimento sustentável dos povos. (MORAES e SOUSA, 2002, p. 3)

Destarte, conclui-se que o Balanço Social emerge como um instrumento crucial nos processos de controle social da gestão, constituindo um mecanismo elementar nos processos de controle a posteriori, alinhado com as propostas de uma administração gerencial guiada para o desenvolvimento sustentável.

\section{Considerações finais}

Em face das reflexões trazidas nesse itinerário científico, nota-se que o desenvolvimento possui dimensões que extrapolam o viés meramente econômico, haja vista que existem outros elementos (sociais, políticos, culturais, ambientais) que exercem influência direta na qualidade e na perenidade do desenvolvimento. Dentro desta perspectiva é que o conceito de desenvolvimento sustentável ganhou força, de modo que mecanismos e instrumentos de controle passaram a ser implementados com o propósito de avaliar, mensurar e otimizar os resultados pretendidos pelas organizações públicas e privadas envolvidas nessa importante missão de promover um desenvolvimento perene e equitativo.

Entre as técnicas analisadas, destaca-se a auditoria como ferramenta apta a identificar, avaliar e discorrer, de forma crível, acerca dos dados apreciados. ${ }^{\top}$ A auditoria, como mecanismo de controle externo, exerce uma importante contribuição ao desenvolvimento das organizações, entretanto, para que o trabalho do auditor seja suficientemente contundente e pluridimensional, urge-se que os demonstrativos fornecidos para análise contemplem indicadores condizentes com a espécie de desenvolvimento que se almeja, ou

\footnotetext{
${ }^{7}$ Lembrando que a dimensão do trabalho do auditor também foi ampliada nos últimos anos, assim como o desenvolvimento, agregando-se elementos sócio-ambientais em seu escopo.
}

seja, que sejam alinhados com o propósito de um desenvolvimento sustentável multifacetado.

Portanto, ferramentas como o Balanço Social emergem como recursos de extrema relevância, haja vista a capacidade de agregar índices de natureza social e ambiental, além dos tradicionais demonstrativos contábeis. Tais indicadores servem de respaldo para uma análise mais ampla, clara e objetiva nos processos de auditoria e mensuração dos resultados, além de instrumentalizar - por meio da transparência - 0 controle social das ações praticadas por organizações adeptas desta técnica de accountability.

Destarte, instrumentos capazes de viabilizar um controle social efetivo passam a adquirir importância singular para a sociedade, justificando-se a ascensão do Balanço Social enquanto mecanismo apto a implementar a participação social e propulsionar o desenvolvimento sustentável. Nesse sentido, conclui-se que os objetivos desse artigo foram plenamente alcançados, uma vez que os instrumentos de controle ora investigados revelaram-se - por deveras - úteis no alcance do desenvolvimento, mormente ao agregar conceitos relativos aos direitos fundamentais que transcendem a ideia de crescimento econômico, além de impulsionar avanços significativos através da participação de organizações públicas e privadas comprometidas com a responsabilidade social.

\section{Referências}

AGUIAR, Andson B. Um modelo de auditoria social. In: II Seminário de Responsabilidade Social e Ambiental. Aquiraz: UFC, 2002.

ALMEIDA, Fernando. O bom negócio da sustentabilidade. Rio de Janeiro: Nova Fronteira, 2002.

ATTIE, William. Auditoria: conceitos e aplicações. 3 ed. São Paulo: Atlas, 1998.

BATISTA, Daniel G. Manual de controle e auditoria: com ênfase na gestão de recursos públicos. São Paulo: Saraiva, 2011.

CHAVES, Renato S. Auditoria e controladoria no setor público: fortalecimento dos controles internos. Curitiba: Juruá, 2009.

FERREIRA, Cleber J. Auditoria social: uma proposta inicial de planejamento de auditoria do balanço social. Florianópolis: UFSC, 2004. 
FRAGA, Rodrigo V.; SILVA, Carlos E. Balanced scorecard: planejamento estratégico no contexto das organizações do terceiro setor. Revista Brasileira de Administração Científica, Aracaju, v. 1, n. 1, dez. 2010.

FREITAS, Ana R.; CABRAL, Augusto; FONTELES, Islane; PESSOA, Maria N.; SANTOS, Sandra. Engajamento dos stakeholders: Uma análise dos relatórios de sustentabilidade de empresas brasileiras do setor financeiro. Revista Portuguesa e Brasileira de Gestão, Lisboa, v. 11, n. 4, out. 2012.

FREITAS, Juarez. Sustentabilidade: direito ao futuro. Belo Horizonte: Fórum, 2011.

FURTADO, Celso. A nova dependência, dívida externa e monetarismo. Rio de Janeiro: Paz e Terra, 1982.

JAIME, Pedro. Dos encontros entre Estado e sociedade civil: um exercício de etnografia do pensamento moderno. Civitas: Revista de Ciências Sociais, Porto Alegre, v. 5, n. 1, jan./jun. 2005.

LEFF, Enrique. Saber ambiental: sustentabilidade, racionalidade, complexidade, poder. 4 ed. Petrópolis: Vozes, 2005.

LIMA, Helena M. O.; PINHEIRO, Hugo M. B. A responsabilidade social da contabilidade: uma proposta de balanço social aplicada ao desenvolvimento local. In: X Seminário de Contabilidade do Estado do Ceará. Fortaleza: UFC, 2004.

MACHADO, João G. R.; PAMPLONA, João B. A ONU e o desenvolvimento econômico: uma interpretação das bases teóricas da atuação do PNUD. Revista Economia e Sociedade, Campinas, v. 17, n. 1, abr 2008.

MARCONI, MarinaA.; LAKATOS, Eva M. Fundamentos de metodologia científica. 7 ed. São Paulo: Atlas, 2010 .

MAXIMIANO, Antonio C. A. Introdução à administração. 5 ed. São Paulo: Atlas, 2000.

MENDES, Roselaine C.; OLEIRO, Walter N.; QUINTANA, Alexandre C. A contribuição da Contabilidade e Auditoria Governamental para uma melhor transparência na gestão pública em busca do combate à corrupção. In: $18^{\circ}$ Congresso Brasileiro de Contabilidade. Gramado: CFC, 2008.

MENDES, Valdenésio $A$. A teoria da dependência à luz da realidade atual. Revista Emancipação, Ponta Grossa, v. 10, n. 1, 2010.
MENEGUSSI, Elires M. M.; IANESKO, José A. A importância da auditoria contábil na prevenção e combate aos erros e às fraudes nas organizações. Revista Eletrônica Lato Sensu - UNICENTRO, Guarapuava, n. 6, jan./dez. 2008.

MORAES, Daniela A.; SOUSA, Almir F. A responsabilidade social e o balanço social da empresa. São Paulo: USP, 2002.

NORTH, Douglass C. Para um país enriquecer. In. Revista Veja. São Paulo: Editora Abril, ed. 1830. 26 nov. 2003.

PAES, José E. S. Fundações, associações e entidades de interesse social: aspectos jurídicos, administrativos, contábeis, trabalhistas e tributários. 7 ed. São Paulo: Forense, 2010.

PAIVA, Rodrigo M. O controle social na Administração Pública: propostas para estruturar e estimular o seu desenvolvimento. João Pessoa: TCE/PB, 2004.

PEDRINI, Dalila M.; OLIVEIRA, Adriana L. A economia solidária como estratégia de desenvolvimento. Revista Emancipação, Ponta Grossa, v. 7, n. 1, 2007.

PERISSATTO, Emília B. Projetos de reforma agrária no noroeste do Paraná: disparidades estruturais e impactos. Maringá: UEM, 2009.

PFITSCHER, Elisete D. Desenvolvimento sustentável e controladoria. Florianópolis: NEMAC/UFSC, 2010.

PINHO, Ruth C. S.; ARAÚJO, Luis C. V. Auditoria em organizações do terceiro setor. In: XI Encontro de Extensão da Universidade Federal do Ceará. Fortaleza: UFC, 2002.

PIRES, Elizangela G. Balanço social: um instrumento de transparência da nova gestão pública. 2009. Florianópolis: UFSC, 2009.

POLANYI, Karl P. A grande transformação: as origens da nossa época. Rio de Janeiro: Campus, 1980.

PUTNAM, Robert D. Comunidade e Democracia: a experiência da Itália moderna. Rio de Janeiro: Editora da Fundação Getúlio Vargas, 1996.

REIS, Carlos N.; MEDEIROS, L. E. Responsabilidade social das empresas e balanço social: meios propulsores do desenvolvimento econômico e social. São Paulo: Atlas, 2011.

RICO, Elizabeth M. A responsabilidade social empresarial e o Estado: uma aliança para o desenvolvimento sustentável. Revista São Paulo em Perspectiva, São Paulo, v. 18, n. 4, Dec. 2004. 
SEN, Amartya. Desenvolvimento como liberdade.

São Paulo: Cia. das Letras, 2000.

SIEBER, Wolfgang $V$. Los actores en la dimensión local. In: GUTIÉRREZ, F. R. (org.). Manual de Desarrollo Local. Gíjon: Trea, 1999.

SILVA, Andreza R. L. Auditoria um recurso social. In: IV Congresso Nacional de Excelência em Gestão e II Simpósio Internacional de Transparência nos Negócios. Rio de Janeiro: UFF, 2008.

SILVA, Antonia; LIMA, Juocerlee T. G.; CABRAL, Augusto C. A.; SANTOS, Sandra M.; PESSOA, Maria N. M. Responsabilidade social empresarial: análise da relação entre a receita líquida e os investimentos socioambientais da Petrobras. Produção Online Revista Científica Eletrônica de Engenharia de Produção, Florianópolis, v. 13, n. 1, jan/mar. 2013.

SILVA, Carlos E.; MOTA, Diego G.; MIRANDA, Fabíola F. O balanço social e sua importância no contexto das organizações. In: VI Simpósio de Excelência em Gestão e Tecnologia. Resende: Dom Bosco, 2009.

SLOMSKI, V. Manual de contabilidade pública: um enfoque na contabilidade municipal. 2 ed. São Paulo: Atlas, 2003.

SOUZA, Nali J. Desenvolvimento Regional. São Paulo: Atlas, 2009.

TREVISAN, Fernando A. Balanço social como instrumento de marketing. RAE-eletrônica - FGVEAESP, São Paulo, v. 1, n. 2, jul/dez. 2002.

TINOCO, João E. P. Balanço social: uma abordagem da transparência e da responsabilidade pública das organizações. São Paulo: Atlas, 2001.

TINOCO, João E. P. Balanço social e o relatório da sustentabilidade. São Paulo: Atlas, 2010.

TRIBUNAL DE CONTAS DA UNIÃO. Manual de auditoria de natureza operacional. Brasília: TCU, Coordenadoria de Fiscalização e Controle, 2000.

TRIBUNAL DE CONTAS DA UNIÃO. Prestação de contas: fundamento da democracia e exercício de cidadania. Brasília: TCU, 2012.

VENTURA, Elvira C. F. Balanço Social dos Bancos/Febraban: uma análise da evolução da responsabilidade social empresarial (RSE). Cadernos EBAPE.BR, Rio de Janeiro, v. 3, n. 3, 2005. 